for considerable periods of time, as is often necessary when using X-rays for therapeutic purposes.

The adaptation of tungsten for this purpose is an example of the great value that lies hidden in the rare and little-known elements, and doubtless other instances of a similar nature will develop as the metals become available.

\section{OSMOTIC PRESSURE OR OSMOTIC SUCTION?}

$\mathrm{I}^{\mathrm{T}}$ has often been assumed that van't Hoff's dis. 1 covery, that the simple gas-law, PV=RT, may be applied to the osmotic pressures of dilute solutions, justifies the view that osmotic pressure is caused by the bombardment of a semi-permeable membrane by the molecules of the solute, just as gas-pressure is caused by the bombardment of the containing vessel by rapidly moving gas-molecules. A recent exposition of this view by Prof. Ehrenfest, in the Proceedings of the Amsterdam Academy (vol. xvii., pp. 1241-1245), has elicited a reply from Prof. J. J. van Laar (ibid., vol. xviii., pp. 184-190), which will be read with very great interest by all those who have seen in the mechanism of osmosis an even more difficult problem than that of expressing the magnitude of the osmotic pressure by means of a mathematical formula. Prof. van Laar's reply is of exceptional value in that it demonstrates the inadequacy of the gas-analogy from the thermodynamic point of view, and so challenges the simple kinetic theory of osmosis on what has generally been supposed to be its strongest ground.

The osmotic pressure may be expressed, according to Van Laar, by the equation,

$$
\mathrm{P}=\mathrm{RT} / v_{0}\left\{-\log (\mathrm{I}-x)+\alpha x^{2}\right\},
$$

where $x$ is the molecular concentration of the dissolved substance, and $\alpha$ is an "influencing" coefficient, which expresses the consequences of the interaction of the molecules of the solvent with those of the dissolved substance. The logarithmic term is an essential feature of the thermodynamic equation, and it is urged that all kinetic theories which lead to expressions without a logarithmic member must be rejected.

The thermodynamic equation, it is true, leads to an expression for dilute solutions which is identical with that of van't Hoff. But in practice it is found that in more concentrated solutions deviations appear which are much smaller than those for non-ideal gases. We may therefore surmise that the so-called osmotic pressure has an entirely different ground from that suggested by van't Hoff's application of the gas-equation, and that there is here no close relation but merely an analogy.

If the osmotic pressure were actually caused by the pressure of the dissolved substance, as Ehrenfest, reviving the old theory, suggests, the pressure of the sugar molecules against the semi-permeable membrane would, in van Laar's opinion, cause the reverse effect to that which is actually observed. No water would pass from the pure solvent through the membrane into the solution, giving rise to a hydrostatic pressure in the osmometer; but, on the contrary, the inward flow of water would be checked, since the pressure in the solution would from the outset be greater than in pure water. In reality, osmotic pressure is caused by the water which penetrates through the semi-permeable membrane, giving rise to a hydrostatic pressure which prevents the further intrusion of the water. This excess of pressure is the so-called "osmotic pressure" of the solution.

Generally speaking, every theory which seeks to interpret osmotic pressure kinetically must be based on the diffusion of the water molecules on the two NO. 2420, VOL. 97$]$ sides of the membrane. If this is done, the logarithmic member arises of its own accord, and finds a place in the equation, whether there is interaction between solvent or solute or not, i.e. the $\alpha$-term appears quite independently of the logarithmic term. In van Laar's opinion, the kinetic interpretation of osmotic pressure, which is always reappearing again in new forms, is moving, and has moved, in a wrong direction, and should again be founded on the simple diffusion phenomenon.

T. M. L.

\section{POST-GRADUATE SCHOLARSHIPS AND FELLOWSHIPS.}

THE new list of scholarships and fellowships offered by the Leeds University has just been issued. It includes some twelve entrance scholarships in arts, science, medicine, and technology, awarded on the results of the matriculation examination of the Joint Matriculation Board, in addition to a certain number (not specified) given by the local education authority. There are also twelve Clothworkers' free studentships in the textile department, and a "William Cooke" scholarship in mining, determined by special examination or selection. In addition to the above are a number of senior scholarships, awarded to students of special merit in the University, by the University, the Leeds City Council, and by various donors who have wished to perpetuate with their names their interest in the University. Such are the Leighton exhibitions established by the trustees of Mrs. Isabel Leighton, of Leeds, the Salt scholarship given by Sir Titus Salt, the John Rutson scholarship, and the Gilchrist studentship in modern languages. The list of post-graduate scholarships and fellowships is a very meagre one. There is one $185^{I}$ exhibition scholarship of $150 l$. tenable for two years, and a number of 1851 exhibition industrial bursaries of $100 l$., both awarded by the I85 $\mathrm{x}$ Exhibition Commissioners, the first in science and the second in some branch of technology. There is, further, a research scholarship in colour chemistry founded by the Clothworkers, and a scholarship in gas engineering endowed by Sir Corbet Woodall. There are also two scholarships in the faculty of medicine. A limited number of research fellowships are also awarded by the University to distinguished graduates; there is one in connection with the fuel department in gas research founded by the Institute of Gas Engineers, and one in colour and textile chemistry.

It is generally recognised by university teachers that the year or years immediately following graduation are in a sense the critical years of a student's career. In science more especially he has laid up a fund of knowledge which he is about to turn to practical account. He has collected a store of potential energy; he has played the róle of an "accumulator" during his university course, and his energy is now to be turned to useful work. In the northern universities at least the graduate has to earn his living, and whilst he is on the look-out for congenial, as well as remunerative, occupation he may often have to wait for many months. It is at this critical time that a post-graduate scholarship, sufficient for the student to keep himself and release his parents from the burden of further naintenance, is invaluable. It is invaluable not merely because it gives him time to look round and relieves him from the necessity of accepting the first vacancy that offers; but because he is learning in that excellent school of research how to use his knowledge and more especially how to depend upon himself.

In the "Scheme for the Organisation and Development of Scientific and Industrial Research" issued by the Board of Education we have the promise of a large extension of post-graduate research studentships and 